\title{
Propriedades farmacológicas de Byrsonima crassifolia (L.) Kunt
}

\author{
Pharmacological properties of Byrsonima crassifolia (L.) Kunt
}

Viviane da Silva Sousa Almeida1,2, Marcos Fernando Câmara Maranhão', Ana Clara Sampaio Lima Vasconcelos ${ }^{1}$, João Víctor Pacheco Florentino', Wesley Costa Barros ${ }^{1}$, Rayla Bezerra Rocha ${ }^{1}$, Kevin Waquim Pessoa Carvalho², Monique Santos do Carmo ${ }^{1,2 *}$

Resumo: Os medicamentos provenientes de plantas estão presentes há milhares de anos na população. Muitas pessoas fazem uso destes produtos na forma de comprimidos, cápsulas, xaropes ou ainda utilizando a planta seca, inteira ou fracionada principalmente na forma de chás. A espécie Byrsonima crassifolia tem um grande potencial de ação terapêutico e está amplamente distribuída na Amazônia Brasileira, América Central e Caribe, sendo conhecida popularmente no Brasil com o nome de muricizeiro. Diversos registros na literatura abordam suas propriedades farmacêuticas, seja para o tratamento do controle da diabetes, depressão e de quadros inflamatórios. Por observar esta vasta quantidade de usos na literatura e, diante da necessidade de um cuidado maior na utilização de medicamentos provenientes de plantas em virtude de agentes tóxicos, foi realizado um estudo de revisão de literatura sobre as propriedades farmacêuticas e o potencial citotóxico de $B$. crassifolia.

Palavras-chave: Byrsonima crassifolia. Muricizeiro. Propriedades farmacêuticas. Potencial citotóxico.

\begin{abstract}
Medicines from plants have been present for thousands of years in the population. Many people make use of these products in the form of tablets, capsules, syrups or even dried, whole or fractionated plant mainly in the form of teas. Byrsonima crassifolia has a great potential of therapeutic action and is widely distributed in the Brazilian Amazon, Central America and the Caribbean, being popularly known in Brazil as muricizeiro. Several records in the literature address its pharmaceutical properties, being registred in the treatment of diabetes, depression and inflammatory conditions. In view of the vast number of uses in the literature, and the need for greater care in the use of plant medicines due to toxic agents, was realized a literature review on the pharmaceutical properties and the cytotoxic potential of $B$. crassifolia.
\end{abstract}

Key words: Byrsonima crassifolia. Muricizeiro. Pharmaceutical properties. Cytotoxic potential.

\footnotetext{
${ }^{1}$ Universidade Ceuma, São Luís, MA, Brasil.

2 Universidade Federal do Maranhão, São Luís, MA, Brasil.

* Autor correspondente - Rua Josué Montello no1, Renascença II - São Luís-MA. CEP 65.075-120.

Telefone: +55 (98) 98868-5248. E-mail: monique.carmo@ceuma.br.
} 


\section{Introdução}

A região Amazônica possui o mais rico repositório de recursos genéticos, inclusive de espécies frutíferas, as quais apresentam diferentes níveis de importância na região. Contudo, a grande maioria dessas espécies ainda é pouco conhecida quanto seu potencial terapêutico'.

Diante do potencial incalculável da biodiversidade brasileira, que poderia ser fonte de novos compostos para 0 desenvolvimento de fármacos, o Brasil possui hoje uma dependência tecnológica em várias áreas, entre elas a saúde humana e a produção de medicamentos.

Este cenário é preocupante, pois a exemplo da produção de fármacos sintéticos, o Brasil, apesar de possuir a maior biodiversidade mundial, pode se tornar apenas um importador de matériasprimas vegetais e reprodutor de formulações fitoterápicas, já que os investimentos em outros países na produção e desenvolvimento de novos alvos terapêuticos são consideravelmente superiores.

Os medicamentos naturais estão em crescimento vertiginoso no mercado, ocupando bastante espaço e substituindo muitos medicamentos sintéticos. Isso acontece em virtude da consciência ambiental das pessoas de que o natural sempre é a melhor escolha, mas apesar dos fitoterápicos serem naturais, eles também tem contraindicações, por isso os cuidados na escolha e dosagem adequadas, pois ambos podem causar efeitos tóxicos ao organismo.

O gênero Byrsonima (família Malpighiaceae) é um dos maiores gêneros distribuídos consistindo de 150 espécies diferentes com predominância em ambientes neotropicais ${ }^{2}$. A espécie Byrsonima crassiflolia (L.) Kunth é a que possui a maior quantidade de trabalhos publicados, especialmente enfatizando 0 potencial farmacológico da planta, que é o objeto de estudo deste trabalho. A planta também tem um amplo uso medicinal em toda a região das Américas Central e do Sul $^{3}$.

A espécie frutífera $B$. crassifolia, também chamada de Murici, como é popularmente conhecida, está presente em toda a região da Amazônia Legal, cerrado, campos e matas costeiras. Adicionalmente, pode ser encontrada em países limítrofes da Amazônia Brasileira, como América Central e Caribe. $O$ fruto possui coloração amarela quando maduro e tem como período de coleta os meses de novembro a março 4 .

Além do fruto ser usado como alimento, diferentes partes da planta têm sido utilizadas pela população como agente terapêutico. Existem muitas evidências científicas que tentam confirmar que $B$. crassifolia contém diferentes propriedades medicinais ${ }^{5}$. Um estudo recente mostrou que o extrato da casca tem ação imunomoduladora estimulando o sistema imune contra Staphylococcus aureus ${ }^{6}$. A atividade antimicrobiana já foi observada em extratos da raiz $^{7}$ e da semente ${ }^{8}$ contra bactérias Gram-positivas e Gramnegativas.

Diante desse contexto, este estudo apresentou como objetivo a elaboração de uma revisão de literatura abordando as propriedades farmacológicas e o potencial de citotoxicidade de diferentes partes de $B$. crassifolia a partir da consulta de artigos indexados publicados nos últimos 20 anos.

\section{Materiais e Métodos}

Esta revisão de literatura utilizou a revisão integrativa enquanto método de pesquisa, visto ser um método amplo que aborda dados da literatura teórica e empírica envolvendo conceitos, revisão de teorias e evidências e tendo como propósito produzir conhecimentos voltados para a solução de problemas de saúde a partir de uma síntese dos materiais pesquisados e da aplicabilidade dos seus resultados ${ }^{9}$. 
A pesquisa foi realizada à partir da consulta das bases de dados Pubmed, Google Scholar, Scopus, Cochrane e ScienceDirect, utilizando-se palavraschave "Byrsonima crassifolia" e "Byrsonima crassifolia and pharmacology". Materiais em inglês e português foram inclusos na revisão.

\section{Resultados}

As propriedades farmacológicas de B. crassifolia já foram comprovadas em diversos estudos, sendo que vários autores chegaram a diferentes conclusões com relação às suas finalidades de usos terapêuticos, entre elas é possível elencar as atividades fotoquimioprotetora, antiinflamatória, antifúngica, antimicrobiana, antidrepressiva e antidiabética (Tabela 1).

Dentre os estudos observados, os trabalhos mais recentes confirmam 0 poder antimicrobiano da planta, juntamente com seu efeito fotoquimioprotetor. Estes estudos e os demais foram feitos utilizando diferentes extratos, sendo o hexano o mais utilizado devido sua melhor atividade na extração dos principais constituintes do metabolismo secundário da planta.

\section{Discussão}

\section{Atividade fotoquimioprotetora e antioxidante}

De acordo com Souza et al. ${ }^{10}$ as frações de extrato parcialmente purificado de folhas de Byrsonima crassifolia protege a pele dos danos causados pela radiação UVB ao agir como antioxidante diminuindo a atividade da mieloperoxidase e a secreção de citocinas pró-inflamatórias IL$1 \beta$ e IL-6 induzida pela radiação UVB $(p<0,05)$. Isso pode ter acontecido através do sinergismo entre os compostos fenólicos, tais como o galato de epigalocatequina e 0 ácido gálico. $\mathrm{O}$ estudo mostrou que a fração do extrato pode proteger a pele contra a inflamação induzida por UVB e o fotoenvelhecimento devido à sua capacidade antioxidante.

Outro trabalho da mesma autora publicado um ano antes demonstrou que os efeitos do extrato etanólico e da fração previnem culturas de queratinócitos do estresse oxidativo induzido pela radiação UVB. Foi observado então que o efeito da peroxidação lipídica in vitro foi mantido em culturas de células e a secreção IL-6 e TNF- $\alpha$ e a ativação de NF-kB foram suprimidas. Mas, como a fração apresentou maior poder de retenção, foi sugerido então sua aplicação tópica na prevenção ou tratamento de danos induzidos pela radiação UVB.

Andrade et al. ${ }^{11}$ afirma que a presença de compostos fenólicos e flavonóides no extrato de $B$. crassifolia foi responsável pela atividade antioxidante $e$ na inibição de possíveis danos oxidativos. Estes compostos são de grande importância na proteção de tecidos vegetais aos fitopatógenos.

\section{Atividade antifúngica}

Um estudo constatou que os extratos etanólicos das folhas de $B$. crassifolia inibem o crescimento micelial de fungos fitopatógenos das espécies Fusarium solani e Sclerotinia sclerotiorum. Essa inibição aconteceu provavelmente devido à ação dos metabólitos secundários, como flavonóides, compostos fenólicos, taninos e antraquinonas e triterpenos (11).

$A$ atividade antifúngica também foi observada em Aspergillus flavus, Epidermophyton jloccosum, Microsporum canis ou $M$. gypseum e Trichophyton rubrum em diferentes tipos de extratos, como etanol, acetato de etila e hexano. 0 extrato que representou a melhor atividade de inibição dos fungos foi 0 etanólico. As partes que inibiram todos os fungos foram a casca, a flor e o fruto, utilizando-se o solvente etanol ${ }^{12}$.

A análise química dos extratos hexânicos, metanólicos e aquosos 


\begin{tabular}{|c|c|c|c|c|c|}
\hline Atividades & Parte da planta & Extratos & Modelo de estudo in vitro e in vivo utilizado & Ano & Referência \\
\hline \multirow[t]{2}{*}{ Antifúngica } & Cascas & Extrato etanólico & Inibição de Fusarium solani e Sclerotinia sclerotiorum & 2017 & 10 \\
\hline & Folhas & $\begin{array}{l}\text { Extrato hexano, } \\
\text { metanol e águaa }\end{array}$ & Inibição de Fusarium oxysporum f. sp. gladíolos & 2014 & 13 \\
\hline \multirow{3}{*}{ Antibacteriana } & Cascas & $\begin{array}{l}\text { Extrato de } \\
\text { acetona }\end{array}$ & Inibição de Staphylococcus aureus & 2017 & 6 \\
\hline & Sementes & $\begin{array}{l}\text { Compostos de } \\
\text { diterpeno } \\
\text { labdano no } \\
\text { extrato hexano }\end{array}$ & $\begin{array}{l}\text { Inibição de Bacillus cereus, Bacillus megaterium, Bacillus } \\
\text { subtilis, Staphylococcus aureus e Escherichia Coli, } \\
\text { Salmonella paratyphi, Pseudomonus aeruginosa, Salmonella } \\
\text { typhi, e Salmonella dysenteriae }\end{array}$ & 2014 & 8 \\
\hline & Raízes e hastes & $\begin{array}{l}\text { Extrato de } \\
\text { hexano, acetato } \\
\text { de etila e } \\
\text { metanol }\end{array}$ & $\begin{array}{l}\text { Inibição de Bacillus subtilis, Escherichia coli, Klebsiella } \\
\text { pneumoniae, Pseudomonas aeruginosa, Salmonella typhi, } \\
\text { Shigella flexneri, Staphylococcus aureus, Staphylococcus } \\
\text { epididermis, Streptococcus pneumoniae e Micrococcus } \\
\text { luteus. }\end{array}$ & 1999 & 7 \\
\hline Fotoquimioprotetora & Folhas & \multicolumn{2}{|r|}{ Camundongos } & 2018 & 1 \\
\hline Antioxidante & Folhas & \multicolumn{2}{|r|}{ Camundongos } & 2018 & 10 \\
\hline Hipoglicêmica & Sementes & \multicolumn{2}{|l|}{ Extrato hexano } & 2016 & 17 \\
\hline \multirow[t]{2}{*}{ Hipolipidêmica } & Sementes & \multicolumn{2}{|c|}{ Extrato hexano } & 2014 & 15 \\
\hline & Sementes e frutos & \multirow{2}{*}{\multicolumn{2}{|c|}{ Extrato clorofórmio, metanol e hexano }} & 2010 & 16 \\
\hline \multirow[t]{2}{*}{ Antiinflamatória } & Sementes & & Extrato clorofórmio, metanol e hexano & 2013 & 21 \\
\hline & Cascas & \multicolumn{2}{|c|}{$\begin{array}{l}\text { Extrato clorofórmio, metanol e éter de Camundongos } \\
\text { petróleo. }\end{array}$} & 2009 & 5 \\
\hline
\end{tabular}

Rev. Investig, Bioméd. São Luís, 10(3): 280-289, 2018 
verificou através da cromatografia gasosa e espectrometria de massas (CG-MS) que 89 compostos voláteis estavam presentes. Estes compostos se distinguiam em quantidade, no qual sesquiterpenos representavam 46,06\%, ácidos graxos $23,6 \%$, diterpenos $14,6 \%$, compostos fenólicos 11, 23\% e monoterpenos $4,7 \%$, todos visualizados a partir de extrato metanólico para atividade antifúngica $^{13}$.

\section{Atividade antibacteriana}

No estudo de Yaseen et al. ${ }^{6}$, constatou-se que o extrato de acetona das cascas de $B$. crassifolia foi capaz de aumentar a atividade antimicrobiana do sangue humano contra Staphylococcus aureus na concentração de $10 \mu \mathrm{g} / \mathrm{mL}$, porém, o próprio extrato não exibiu impacto antimicrobiano direto. Segundo os autores, o composto antimicrobiano ou modulador de neutrófilos nos extratos ainda não está definido. Neste estudo, os autores postularam que a capacidade para eliminar microrganismos patogênicos pode ser eficaz a partir da estimulação do sistema imunológico. Esta eficiência na defesa de hospedeiros contra patógenos invasores pode apoiar os tratamentos convencionais baseados em antibióticos ou fornecer uma nova estratégia contra bactérias resistentes a antibióticos.

Para avaliar a capacidade antimicrobiana de compostos e diterpenos da fração dos extratos hexânicos de $B$. crassifolia, Muniz-Ramirez et al. ${ }^{8}$, observaram o crescimento dos halos de inibição de diferentes cepas bacterianas. Os resultados mostraram uma forte atividade (inibição zona $\geq 20$ milímetros), moderada atividade (zona de inibição < 20-12 mm) e sem inibição (zona < $12 \mathrm{~mm}$ ). O halo de maior tamanho foi visto contra a bactéria $S$. paratyphi $(23,87 \pm 0,65 \mathrm{~mm})$, seguido de $P$. aeruginosa $(21,45 \pm 0,53$ $\mathrm{mm}), S$. Typhi $(20,72 \pm 0,56 \mathrm{~mm})$ e $B$. subtilis $(20,89 \pm 2,90 \mathrm{~mm})$. Porém, o extrato não apresentou elevado poder de inibição para algumas bactérias, entre elas $B$. megaterium $(19,20 \pm 3,42 \mathrm{~mm}) B$. cereus $(18,76 \pm 0,68)$, Staphylococcus aureus (17.95 \pm 1,78), Escherichia coli $(13,35 \pm 1,43)$ e $S$. dysenteriae $(16,52 \pm$ 1,88). Já outras não apresentaram nenhum efeito antimicrobiano aparente, como Vibrio mimicus (12,08 $\pm 4,12)$, Sarcinia lutea $(12,17 \pm 1,23), \quad V$. parahemolyticus $(11,87 \pm 4,20)$ e Shigella boydii $(0,0 \mathrm{~mm})$. Os resultados sugerem testar estes extratos em outras bactérias comumente resistentes a medicamentos.

A atividade antibacteriana também pode ser encontrada nas raízes e nas hastes da planta. Estas atividades foram observadas com os extratos hexano, acetato de etila e metanol em cepas de Bacillus subtilis, Escherichia coli, Klebsiella pneumoniae, Pseudomonas aeruginosa, Salmonella typhi, Shigella flexneri, Staphylococcus aureus, Staphylococcus epididermis, Streptococcus pneumoniae e Micrococcus luteus, no qual foram observadas zonas de inibição variando de 17 a $26 \mathrm{~mm}$. Nestes experimentos, o extrato acetato de etila das raízes e caule foram os mais eficazes, mostrando atividade contra todas as bactérias testadas. No extrato metanólico das raízes observou-se atividade apenas para as espécies $K$. pneumoniae, S. aureus, E. coli e S. Typhi. Por outro lado, os resultados foram ainda menos satisfatórios com 0 extrato metanólico das hastes e em ambos os extratos hexânicos ${ }^{7}$. $\mathrm{Na}$ análise fitoquímica do extrato acetato de etila das raízes foram observados flavonóides, saponinas e glicosídeos, mas de acordo com os autores, apenas a presença de flavonóides e glicosídeos já indicaria atividade antibacteriana do extrato ${ }^{14}$.

\section{Atividade hipoglicêmica hipolipidêmica}

Gutierrez et al. ${ }^{15}$ demonstrou que o extrato hexano de sementes de $B$. crassifolia em ratos diabéticos diminui os 
níveis de glicose de uma forma representativa em comparação com ratos não diabéticos (de 349,7mg/dl para $99,8 \mathrm{mg} / \mathrm{dl}$ ). No entanto, quanto verificadas estas mesmas doses para extratos clorofórmio e metanol, não foi possível observar tal propriedade hipoglicêmica. Além do decréscimo no nível de glicose, observou-se também uma diminuição no colesterol total e nos níveis de triglicerídeos dos ratos diabéticos. Sabese então, que o extrato de $B$. crassifolia pode ajudar no controle de radicais livres e na proteção às células contra o estresse oxidativo, suprimindo danos nas células pancreáticas em ratos diabéticos tipo I induzidos por estreptozotocina.

Um estudo semelhante dos mesmos autores utilizando as sementes e os frutos de $B$. crassifolia foi publicado um pouco antes, abordando animais tratados com extratos hexânicos e clorofórmicos para avaliar o nível de glicose no sangue de ratos diabéticos ${ }^{16}$. A partir deste resultado, verificou-se que o extrato hexano é o mais ativo quando comparado ao clorofórmio na redução dos níveis de glicose do sangue. $O$ estudo avaliou os extratos hexânicos de sementes e frutos e concluiu que ambos apresentam efeitos benéficos sobre a hiperlipidemia, a hipoinsulinemia, estresse oxidativo e a formação de AGEs (produtos finais de glicação avançada). Este trabalho demonstrou que a descoberta dos extratos de $B$. crassifolia agindo nestes mecanismos do organismo dos ratos pode ajudar na prevenção da diabetes ou retardar o seu aparecimento.

As sementes são grandes fontes de propriedades hipoglicêmicas, antioxidante e tem um papel importante na redução de níveis de glicose do sangue, avaliada a partir de extrato hexano administrado em camundongos diabéticos induzidos por estreptozotocina ${ }^{17}$.

As atividades hipoglicêmicas e hipolipidêmicas mostram uma nova abordagem de tratamento para problemas como obesidade e doenças cardiovasculares, por exemplo, melhorando consideravelmente

a qualidade de vida da população.

\section{Atividade cicatrizante}

O extrato hexano de sementes foi utilizado em ratos diabéticos para avaliar o potencial de cicatrização. Um aumento na contração da ferida indicou um resultado significativo quanto a esta parte da planta, no qual foi observado que no $14^{\circ}$ dia $(p<0,05)$ havia $100 \%$ de contração da ferida em comparação com os grupos controles: normal e com pomada simples (nitrofurazona). Os resultados mostraram que o extrato aumentou significativamente o teor de hidroxiprolina (níveis de colágeno), proteína total e DNA resultando em uma taxa de contração e período de epitelização superior aos grupos controles. Neste caso, o estudo mostrou o extrato hexano como um candidato potencial para cicatrização de feridas $^{18}$. Estes resultados podem contribuir no processo de melhora do quadro de saúde das pessoas diabéticas, pois este produto natural com propriedades terapêuticas pode agir de forma mais rápida nos ferimentos atuando como cicatrizante.

O uso destes produtos é possível para um universo bem maior de pessoas, incluindo os diabéticos. Os que sofrem de ferimentos provenientes de feridas crônicas severas costumam ficar internados por um longo período, sendo que muitas vezes um processo infeccioso se acelera e dificulta ainda mais a recuperação dos pacientes. Este tratamento prolongado e oneroso deve-se à infecção persistente de uma complexa população microbiana, incluindo espécies aeróbicas e anaeróbicas no leito da ferida. Esta microflora afeta as condições gerais, nutricionais, de perfusão e oxigenação dos tecidos, favorecendo a cronificação da lesão ${ }^{19}$.

Entre os microrganismos mais comumente encontrados em ulcerações está o Staphylococcus aureus e 
Pseudomonas aeruginosa. No entanto, é importante salientar que bactérias anaeróbias são também muito prevalentes, como os gêneros Bacteroides, Peptoniphilus, Finegoldia, Anaerococcus e Clostridium ${ }^{20}$.

As opções de tratamento de feridas cutâneas crônicas são amplas, pois estas lesões apresentam etiologia e características diversas, o que torna 0 tratamento dispendioso e com grande diversidade de propostas terapêuticas. Estas incluem administração medicamentosa, aplicação de curativos com diversos tipos de cobertura e, até mesmo, cirurgia. De forma geral, o objetivo de qualquer um destes tratamentos é a cura da úlcera e a prevenção da sua recorrência, e os extratos de $B$. crassifolia podem se tornar alternativas viáveis, ágeis e seguras neste processo de evolução durante a cicatrização.

\section{Atividade anti-inflamatória}

O efeito anti-inflamatório das sementes de $B$. crassifolia foi avaliado a partir de um edema no ouvido e na pata de ratos com extratos hexano, metanol e clorofórmio. Nestes experimentos, os autores puderam observar que o extrato hexano das sementes exibiu atividade antiinflamatória considerável em modelos agudos e crônicos com contribuição nas ações inibitórias de respostas inflamatórias ${ }^{21}$.

No entanto, quando observados os dados de outros autores a respeito de outro experimento, também abordando edemas em orelhas de ratos, foi observado que o extrato de clorofórmio das cascas de $B$. crassifolia apresentou uma melhor atividade, uma vez que o edema foi reduzido em até $71 \%$, o mesmo edema foi reduzido em apenas $38 \%$ no extrato com éter de petróleo da casca, a redução foi ainda menor no extrato metanol, menos de $20 \%$ de redução. Como referência, o fármaco antiinflamatório indometacina $\left(100 \mathrm{~g} / \mathrm{cm}^{2}\right)$ reduziu a resposta edematosa em $60 \%$. Este trabalho ressaltou a importância de plantas com atividades farmacológicas e também abordou os tipos mais indicados de solventes para a preparação dos extratos ${ }^{5}$.

\section{Atividade antidepressiva}

De acordo com Herrera-Ruiz et al. ${ }^{22}$, os extratos de $B$. crassifolia apresentam efeitos antidepressivos, no entanto, outras atividades farmacológicas estudadas como ansiolíticos, sedativo, anticonvulsionante ou com efeitos sobre o sistema nervoso entérico não foram observados. Os autores acreditam que a propriedade antidepressora esteja associada à grande quantidade de flavonóides dentre os compostos presentes. Esta propriedade foi bem evidenciada em extrato metanólico de folhas, não observando o mesmo efeito significativo no extrato hexano.

O teste para avaliar os efeitos depressivos nos ratos, apesar de não esclarecerem os mecanismos de ação do extrato, foi feito da seguinte forma no ensaio: os ratos eram forçados a nadar em um espaço restrito sem escapatória, desta forma, no desespero de acharem uma saída eles desenvolviam um estado de imobilidade. A partir da ingestão de extratos metanólicos, esta atividade foi revertida, por isso, acredita-se que o conteúdo do extrato, por ser rico em flavonóides com doses de quercetina e rutina, tenha induzido um efeito antidepressivo no teste de natação forçada ${ }^{22}$.

\section{Potencial de citotoxidade}

Para fazer uso das diferentes propriedades farmacológicas da planta $B$. crassifolia é importante conhecer primeiramente o perfil de citotoxicidade das partes comumente utilizadas para fins 
terapêuticos, principalmente a folha e a semente, que fazem parte dos ingredientes de extratos para várias finalidades.

Outra comparação do perfil de toxicidade é observada quando o extrato e a fração dele são utilizados em células de animais. Um estudo recente observou que o perfil citotóxico em culturas de células na avaliação do efeito fotoquimioprotetor de UVB foi observado 0 extrato em comparação com a fração, a partir daí pode-se perceber que a fração apresentava quantidades menores de compostos citotóxicos e altas quantidades de antioxidantes compostos em relação ao extrato. O processo de fracionamento proporcionou também um aumento na concentração de compostos fenólicos. Neste ensaio para o efeito fotoquimioprotetor, a concentração máxima de extrato e fração estabelecida quando testada em porcos foi de $5 \mu \mathrm{g} /$ $\mathrm{mL}$, e a concentração máxima padrão foi de $10 \mu \mathrm{g} / \mathrm{mL}^{23}$.

Os extratos de hexano, clorofórmio e metanol dos frutos e sementes $B$. crassifolia também não apresentaram efeitos citotóxicos para animais vertebrados, neste caso foram utilizadas doses crescentes de 1, 2 e $3 \mathrm{~g} / \mathrm{kg}$ peso corporal em ratos. Mesmo após o período de observação, não foram verificadas alterações no seu perfil comportamental, neurológico ou autonômico. Os ratos não apresentaram qualquer letalidade ou morte. A toxicidade aguda foi então testada até uma alta concentração de 3 $\mathrm{g} / \mathrm{kg}$ de peso corporal, mas mesmo a dose máxima não apresentou alterações comportamentais significativas ou sinais de toxicidade. Em virtude da inexistência de efeitos tóxicos dos extratos de frutos e sementes de $B$. crassifolia e dos resultados promissores em relação ao seu uso no diabetes em ratos, são sugeridas frações farmacológicas da espécie para serem usadas em humanos após a realização de outros estudos clínicos ${ }^{16}$.

\section{Conclusão}

Muitos destes estudos apresentam resultados promissores como excelentes fontes terapêuticas, no entanto, devido principalmente ao uso indiscriminado ou inadequado feito pela população, podem se tornar fontes tóxicas para o organismo. E o conhecimento acerca das propriedades citotóxicas das partes da planta de $B$. crassifolia, torna-se limitado devido à escassez de publicações enfatizando suas doses e contraindicações, muitos estudos ressaltam apenas suas propriedades farmacológicas e fitoquímicas sem fazer os testes de citotoxicidade.

Com os resultados apontados nesta revisão percebe-se que ao longo destes vinte anos de pesquisa, muitas descobertas com o enfoque farmacológico foram feitas envolvendo a espécie $B$. crassifolia. A maior parte destes estudos não avaliou o potencial citotóxico da planta, isso pode ter acontecido em virtude de trabalhos publicados anteriormente apontando a espécie como uma boa alternativa em usos medicinais e repassando uma segurança na sua utilização. Mas, observa-se também que muitos destes estudos não tiveram continuidade, não informando também os compostos responsáveis por tais atividades farmacológicas para avaliar os efeitos tóxicos destas substâncias para a espécie humana.

Os registros apresentados demonstram a necessidade de uma investigação mais aprofundada dos principais componentes ativos das partes da planta, algumas destas pesquisas, como por exemplo utilizando o extrato para prevenção dos raios UVB, estão em andamento, outras no entanto, apenas afirmam a importância de estudos complementares para investigar qual(s) princípio(s) exercem os efeitos farmacológicos da planta.

A compreensão dos mecanismos envolvidos na produção de metabólitos secundários pelos vegetais pode auxiliar 
na geração de fitomedicamentos seguros quanto aos seus efeitos farmacológicos e toxicológicos.

\section{Referências}

1. Lorenzi H. Árvores brasileiras: manual de identificação e cultivo de plantas arbóreas nativas do Brasil. $2^{\mathrm{a}}$ edição. Nova Odessa, SP: Editora Plantarum; 1998.

2. Teixeira LAG, Machado IC. Sistema de polinização e reprodução de Byrsonima sericea DC (Malpighiaceae). Acta Botanica Brasilica. 2000;14(3):347-57.

3. Guilhon-Simplicio F, PEREIRA MdM. Aspectos químicos e farmacológicos de Byrsonima (Malpighiaceae). Química Nova. $2011 ; 34(6): 1032-41$.

4. Brasil, Ministério da Saúde. Alimentos regionais brasileiros. Brasília; 2015.

5. Maldini M, Sosa S, Montoro P, Giangaspero A, Balick M, Pizza C, et al. Screening of the topical anti-inflammatory activity of the bark of Acacia cornigera Willdenow, Byrsonima crassifolia Kunth, Sweetia panamensis Yakovlev and the leaves of Sphagneticola trilobata Hitchcock. Journal of ethnopharmacology. 2009;122(3):430-3.

6. Yaseen R, Branitzki-Heinemann $\mathrm{K}$, Moubasher H, Setzer W, Naim H, von Köckritz-Blickwede M. In Vitro Testing of Crude Natural Plant Extracts from Costa Rica for Their Ability to Boost Innate Immune Cells against Staphylococcus aureus. Biomedicines. 2017;5(3):40.

7. Martínez-Vázquez $M$, Gonzalez-Esquinca $A$, Luna LC, Gutiérrez MM, García-Argáez A. Antimicrobial activity of Byrsonima crassifolia (L.) HBK. Journal of Ethnopharmacology. 1999;66(1):79-82.

8. Muñiz-Ramirez A, Pérez-Gutiérrez RM, GarciaBaez E, Mota-Flores JM. Antimicrobial activities of diterpene labdane from seeds of Byrsonima crassifolia. Boletín Latinoamericano y del Caribe de Plantas Medicinales y Aromáticas. 2014;13(1).

9. Whittemore R, Knafl K. The integrative review: updated methodology. Journal of advanced nursing. 2005;52(5):546-53.
10. Souza RO, Alves GdAD, Aguillera ALS, Rogez $\mathrm{H}$, Fonseca MJV. Photochemoprotective effect of a fraction of a partially purified extract of Byrsonima crassifolia leaves against UVBinduced oxidative stress in fibroblasts and hairless mice. Journal of Photochemistry and Photobiology B: Biology. 2018;178:53-60.

11. Andrade B, Matias R, Corrêa B, Oliveira A, Guidolin D, Roel A. Phytochemistry, antioxidant potential and antifungal of Byrsonima crassifolia on soil phytopathogen control. Brazilian Journal of Biology. 2018;78(1):140-6.

12. Caceres A, Lopez B, Juarez X, Del Aguila J, Garcia S. Plants used in Guatemala for the treatment of dermatophytic infections. 2. Evaluation of antifungal activity of seven American plants. Journal of Ethnopharmacology. 1993;40(3):207-13.

13. Pizana CG, Necha LB, Banos SB, Gomez MYR, Barrera LG. Chemical composition and antifungal activity of leaf powders and extracts of Byrsonima crassifolia (L.) Kunth, Ocimum basilicum L. Persea americana Miller., Psidium guajava L. and Spondias purpurea L. from Morelos, Mxico. Afr J Microbiol Res. 2014;8:3875-81.

14. Jeffrey B, Herbert B, Gerald P. Phytochemical dictionary, A Handbook of Bioactive Compounds from Plants. Taylor \& Francis Ltd, London, United Kingdom; 1993.

15. Gutierrez RMP, Flores JMM. Effect of chronic administration of hexane extract of Byrsonima crassifolia seed on $\beta$-cell and pancreatic oxidative parameters in streptozotocin-induced diabetic rat. African Journal of Traditional, Complementary and Alternative Medicines. 2014;11(2):231-6.

16. Perez-Gutierrez RM, Muñiz-Ramirez A, Gomez YG, Ramírez EB. Antihyperglycemic, antihyperlipidemic and antiglycation effects of Byrsonima crassifolia fruit and seed in normal and streptozotocin-induced diabetic rats. Plant foods for human nutrition. 2010;65(4):350-7.

17. Gutiérrez RMP, Ramirez AM. Hypoglycemic Effects of sesquiterpene lactones from Byrsonima crassifolia. Food science and biotechnology. 2016;25(4):1135-45.

18. Gutiérrez RMP, Ramirez AM. Hexane extract of the seeds of Byrsonima crassifolia accelerates wound healing in streptozotocin-induced diabetic rats. Chinese Journal of Integrative Medicine. 2013:1-7.

19. Dowd SE, Sun Y, Secor PR, Rhoads DD, Wolcott BM, James GA, et al. Survey of bacterial diversity in chronic wounds using pyrosequencing, DGGE, and full ribosome 
shotgun sequencing. BMC microbiology. 2008;8(1):43.

20. Rhoads DD, Wolcott RD, Sun Y, Dowd SE. Comparison of culture and molecular identification of bacteria in chronic wounds. International journal of molecular sciences. 2012;13(3):2535-50.

21. Ramirez AM, Cotera LBF, Gutierrez R. Antiinflammatory activity of the hexane extract of byrsonimacrassi folia seeds in experimental animal models. Alter Ther. 2013;19:26-36.

22. Herrera-Ruiz M, Zamilpa A, González-Cortazar M, Reyes-Chilpa R, León E, García M, et al. Antidepressant effect and pharmacological evaluation of standardized extract of flavonoids from Byrsonima crassifolia. Phytomedicine. 2011;18(14):1255-61.

23. Souza RO, Alves GdAD, Forte ALSA, Marquele-Oliveira $F$, da Silva DF, Rogez $\mathrm{H}$, et al. Byrsonima crassifolia extract and fraction prevent UVB-induced oxidative stress in keratinocytes culture and increase antioxidant activity on skin. Industrial crops and products. 2017;108:485-94. 